\title{
Efficacy of clonidine in a patient with refractory hypertension and chronic renal failure exhibiting neurovascular compression of the rostral ventrolateral medulla
}

Hypertension Research (2009) 32, 227-228; doi:10.1038/hr.2009.1; published online 13 February 2009

To the editor:

The rostral ventrolateral medulla (RVLM) is an important center for the regulation of sympathetic and cardiovascular activities. ${ }^{1}$ An association between neurovascular compression (NVC) of the RVLM and essential hypertension (EH) has been suggested. ${ }^{2,3}$ Microvascular decompression (MVD) of the RVLM decreases blood pressure (BP) in hypertensive patients with NVC of the RVLM. ${ }^{2}$ Earlier, we reported a patient with EH and NVC of the RVLM who exhibited normalization of $\mathrm{BP}$ and decreases in sympathetic nerve activity (SNA) by MVD of the RVLM. ${ }^{4}$ Therefore, MVD of the RVLM could be a useful therapeutic strategy to reduce $\mathrm{BP}$ in these patients. Herein, we report a patient with chronic renal failure (CRF) and refractory hypertension with NVC of the RVLM who exhibited prominent BP decrease and improved renal function with an $\alpha 2$ adrenergic agonist, clonidine.

The patient was a 54-year-old man with CRF and was referred to our hospital in August 2005 because of refractory hypertension. He was diagnosed with $\mathrm{EH}$ and diabetes mellitus in 1985, and with CRF in 2003. Office BP was $182 / 100 \mathrm{~mm} \mathrm{Hg}$ and pulse rate $(\mathrm{PR})$ was 62 beats $\mathrm{min}^{-1}$ under treatment with $80 \mathrm{mg}$ nifedipine controlled release, $60 \mathrm{mg}$ olmesartan, $8 \mathrm{mg}$ doxazosin, $10 \mathrm{mg}$ carbezirol, $60 \mathrm{mg}$ furosemide and $180 \mathrm{mg}$ azosemide at the first visit. Results of the initial tests were as follows: urinary protein, $551.7 \mathrm{mg}$ per $\mathrm{g}$ Cre; blood urea nitrogen, $48 \mathrm{mg}$ per $100 \mathrm{ml}$; serum creatinine, $4.15 \mathrm{mg}$ per $100 \mathrm{ml}$; hemoglobin Alc, 6.5\%; and plasma norepinephrine (NE) concentra- tion, $0.57 \mathrm{ng} \mathrm{ml}^{-1}$ (normal range: 0.15 $0.57 \mathrm{ng} \mathrm{ml}^{-1}$ ). Echocardiogram revealed left ventricular hypertrophy (LVH) and normal systolic function. ${ }^{131}$ I-meta-iodobenzylguanidine scintigraphy revealed no abnormal uptakes. Magnetic resonance imaging showed NVC of the RVLM by left posterior inferior cerebellar artery (Figure 1). Additional treatment with $450 \mu \mathrm{g}$ clonidine induced rapid reduction in BP associated with decreases in PR and plasma NE levels (0.94 and $0.39 \mathrm{ng} \mathrm{ml}^{-1}$ just before and 4 weeks after clonidine treatment, respectively) (Figure 2). Although the doses of antihypertensive drugs were gradually reduced, BP remained low. Serum creatinine gradually reduced to $3.18 \mathrm{mg}$ per $100 \mathrm{ml}$ in August 2007. Hemoglobin A1c was not greatly changed (ranged around $6.5 \%$ ) during the course.

This case exhibited refractory hypertension, CRF and NVC of the RVLM and increased plasma NE concentration. Increased SNA is observed in hypertensive patients with NVC of the RVLM. ${ }^{5-7}$ Therefore, it was anticipated that NVC of the RVLM contributed, at least in part, to the increased SNA and BP. Additional treatment with clonidine was selected instead of MVD of the RVLM, as complete remission of hypertension could not be expected because of the possible existence of renoparenchymal hypertension even though invasive MVD of the RVLM was performed. Additional treatment with clonidine successfully reduced BP and plasma NE levels and caused a gradual reduction in serum creatinine. Considering that strict control of BP is important in the treatment of chronic kidney disease, ${ }^{8}$ it is likely that successful BP reduction by this regimen contributed to the renoprotective effect in this case.

Involvement of increased SNA is reported not only in NVC of the RVLM but also in CRF, LVH, and administration of antidiuretic agents. Therefore, it is possible that the mechanism of increased SNA in this case was complex. Clonidine, an $\alpha 2$ adrenergic agonist, elicits hypotensive and sympathoinhibitory effects by action mainly on the RVLM. ${ }^{9}$ It is likely that NVC of the RVLM, at least partially, contributed to increased SNA and
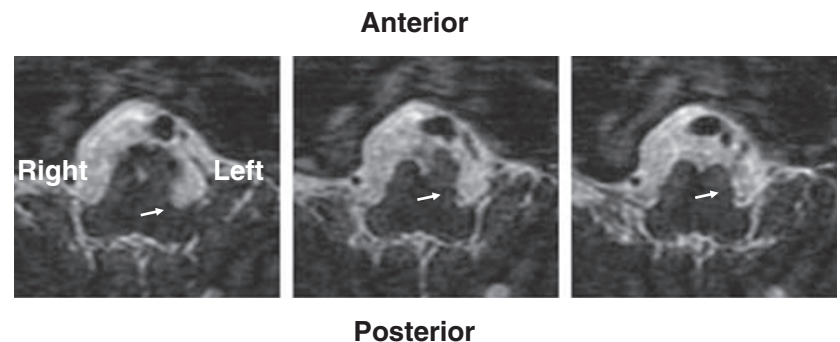

Posterior

Figure 1 Axial magnetic resonance images. The posterior inferior cerebellar artery is compressing the surface of the rostral ventrolateral medulla (RVLM) (arrows). 


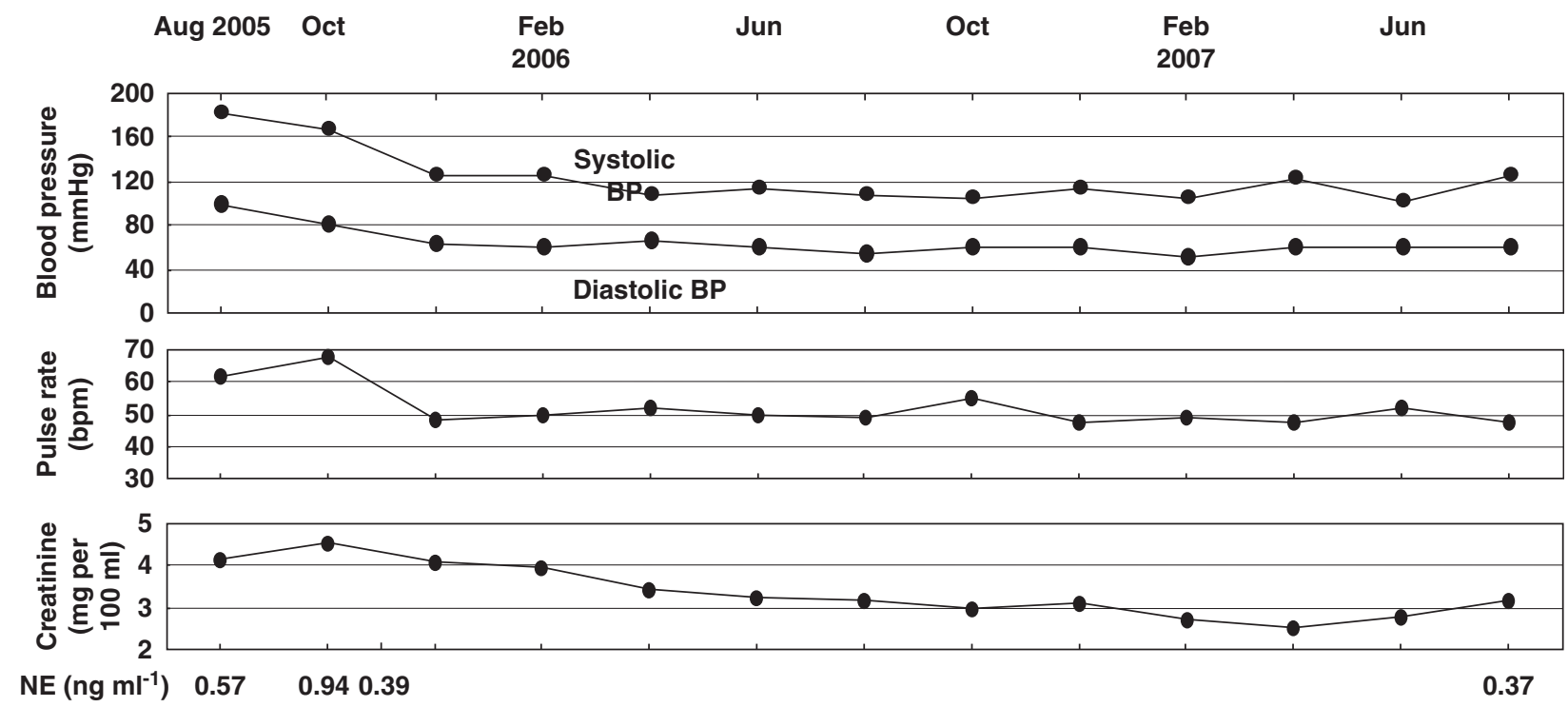

\begin{tabular}{|c|c|}
\hline & Clonidine $450 \mu \mathrm{g}_{\text {day }}-1$ \\
\hline & Nifedipine controlled release $80 \mathrm{mg} \mathrm{day}^{-1}$ \\
\hline \multirow{2}{*}{$\begin{array}{l}\text { Olmesartan } \\
60 \mathrm{mg} \mathrm{day}^{-1}\end{array}$} & $40 \mathrm{mg} \mathrm{day}^{-1}$ \\
\hline & Doxazosin $8 \mathrm{mg}$ day $^{-1}$ \\
\hline \multicolumn{2}{|c|}{ Carbezirol $10 \mathrm{mg}$ day $^{-1}$} \\
\hline $\begin{array}{l}\text { Furosemide } \\
60 \mathrm{mg} \mathrm{day}^{-1}\end{array}$ & $40 \mathrm{mg}$ day $^{-1}$ \\
\hline Azosemide $180 \mathrm{mg} \mathrm{day}^{-1}$ & $120 \mathrm{mg} \mathrm{day}^{-1}$ \\
\hline
\end{tabular}

Figure 2 Clinical course. NE, norepinephrine.

$\mathrm{BP}$ in this case, because clonidine showed excellent efficacy in reducing elevated SNA and BP.

This case suggests that antihypertensive medical treatment with sympatholytic agents acting on the RVLM may be useful in hypertensive patients with NVC of the RVLM. To confirm this finding, further studies in a series of similar patients are needed. Also, studies examining the effects of other $\alpha 2$ adrenergic agonists, such as guanfacine, guanabentz and $\alpha$-methyldopa, are required. Clinical studies examining the effects of antihypertensive agents to reduce SNA (clonidine and the L- and N-type calcium channel blocker) in patients with hypertension are in progress, and if the present findings are confirmed, assessment of whether NVC of the RVLM exists or not will be recommended in patients with refractory hypertension.

Satoshi Morimoto ${ }^{1}$, Yasuko Aota ${ }^{1}$, Takao Sakuma ${ }^{1}$, Akira Ichibangase ${ }^{2}$,
Koshi Ikeda ${ }^{3}$, Satoshi Sawada ${ }^{3}$ and Toshiji Iwasaka ${ }^{1}$

${ }^{1}$ Second Department of Internal Medicine, Kansai Medical University, Hirakata City,

Osaka, Japan; ${ }^{2}$ Department of Internal Medicine, Komatsu Hospital, Neyagawa City, Osaka, Japan and ${ }^{3}$ Department of Radiology,

Kansai Medical University,

Hirakata City, Osaka, Japan

E-mail: morimots@hirakata.kmu.ac.jp

1 Dampney RA, Goodchild AK, Robertson LG, Montgomery W. Role of ventrolateral medulla in vasomotor regulation: a correlative anatomical and physiological study. Brain Res Rev 1982; 249: 223-235.

2 Jannetta PJ, Segal R, Wolfson SK. Neurogenic hypertension: etiology and surgical treatment. I. Observations in 53 patients. Ann Surg 1985; 201: 391-398.

3 Morimoto S, Sasaki S, Miki S, Kawa T, Itoh H, Nakata T, Takeda K, Nakagawa M, Kizu O, Furuya S, Naruse S, Maeda T. Neurovascular compression of the rostral ventrolateral medulla related to essential hypertension. Hypertension 1997; 30 (Part 1): 77-82.
4 Morimoto S, Sasaki S, Takeda K, Furuya S, Naruse S, Matsumoto K, Higuchi T, Saito M, Nakagawa M. Decreases in blood pressure and sympathetic nerve activity by microvascular decompression of the rostral ventrolateral medulla in essential hypertension. Stroke 1999; 30: 1707-1710.

5 Morimoto S, Sasaki S, Itoh H, Nakata T, Takeda K, Nakagawa M, Furuya S, Naruse S, Fukuyama R, Fushiki S. Sympathetic activation and contribution of genetic factors in hypertension with neurovascular compression of the rostral ventrolateral medulla. J Hypertens 1999; 17: 1577-1582.

6 Makino $\mathrm{Y}$, Kawano $\mathrm{Y}$, Okuda $\mathrm{N}$, Horio $\mathrm{T}$, I washima $\mathrm{Y}$, Yamada N, Takayama M, Takishita S. Autonomic function in hypertensive patients with neurovascular compression of the ventrolateral medulla oblongata. J Hypertens 1999; 17: 1257-1263.

7 Sendeski MM, Consolim-Colombo FM, Leite CC, Ribira MC, Lessa P, Krieger EM. Increased sympathetic nerve activity correlates with neurovascular compression at the rostral ventrolateral medulla. Hypertension 2006; 47: 988-995.

8 Bakris GL, Williams M, Dworkin L, Elliott WJ, Epstein M, Toro R, Tuttle K, Douglas J, Hsueh W, Sowers J. Preserving renal function in adults with hypertension and diabetes: a consensus approach. Am J Kidney Dis 2000; 36: 646-661.

9 Ruffolo Jr RR, Nichols AJ, Stadel JM, Hieble JP. Pharmacologic and therapeutic applications of 2-adrenoceptor subtypes. Annu Rev Pharmacol Toxicol 1993; 33 : 243-279. 